\section{Case of Cronkhite-Canada Syndrome with Associated Jejunal Diverticulosis}

Brit. med.7., 1967, 4, 601-602

The association of gastrointestinal polypi with diffuse alopecia and nail dystrophy was first recorded by Cronkhite and Canada (1955). This paper records the ninth patient with this syndrome.

\section{CASE REPORT}

The patient was a schoolmaster aged 60 . In 1957 diffuse alopecia and "unusual nails" were noted during investigations for dyspepsia. Laparotomy revealed a nodular pancreas, and chronic pancreatitis these were polypi was confirmed by gastroscopy and gastric biopsy. The investigations indicated the presence of hypomagnesaemia, hypocalcaemia, and hypokalaemia, presumably secondary to jejunal diverticulosis. At this time there was no conclusive evidence of more generalized intestinal malabsorption. Oral replacement therapy with magnesium hydroxide, vitamin $\mathrm{D}$, calcium gluconate, and potassium citrate produced an improvement in his general condition, but between 1963 and 1966 he complained of intermittent upper abdominal discomfort, vomiting, and anorexia. His weight fluctuated considerably and on two occasions he was admitted to hospital for blood transfusion because of occult gastrointestinal bleeding. A string test suggested bleeding from the jejunum.

Investigations of intestinal function in 1967 revealed more generalized malabsorption (see Table). The presence of excess urinary indican, together with an excellent response to antibiotic therapy (ampicillin $250 \mathrm{mg}$. q.i.d.), suggested that a change in bacterial flora may have been responsible for the enteropathy.

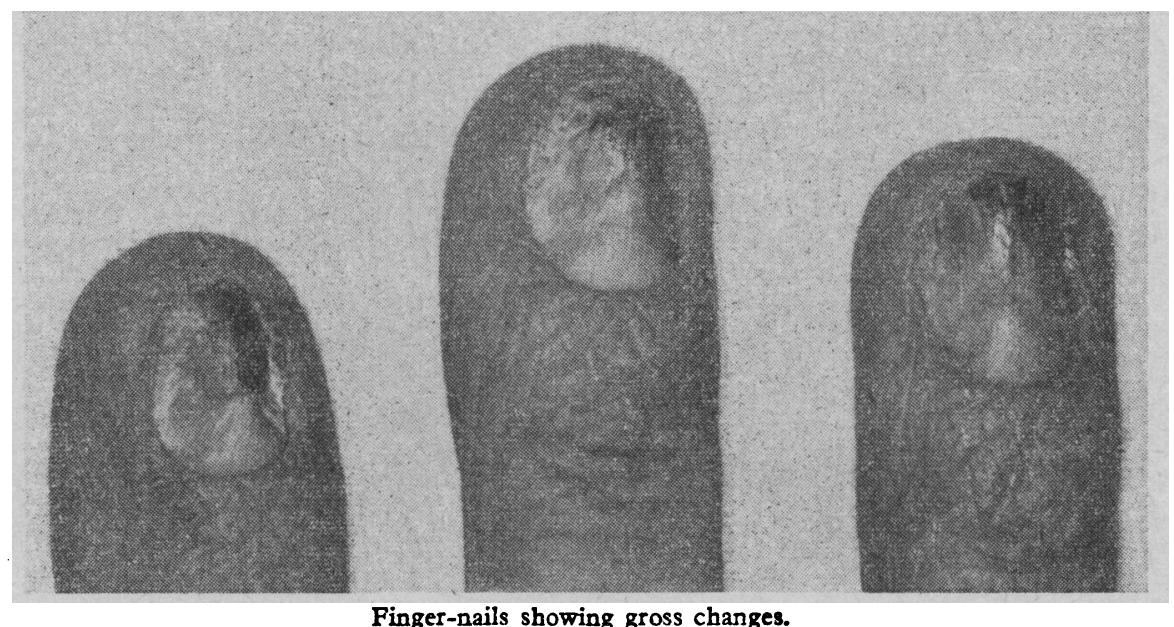

was suspected. The following year a gastroenterostomy was performed, but at neither operation was any abnormality of stomach or small bowel reported. In 1962 an epileptic fit necessitated a further hospital admission. His general health was good, though paraesthesiae in the hands had been noted for two weeks. His bowel actions were normal.

On examination no abnormal pigmentation of the skin or mucous membranes was seen. He had diffuse non-scarring alopecia and the body hair was also scanty. All finger-nails and toe-nails, except for the right fourth and fifth toes, were strikingly abnormal (see Fig.). In the proximal half the normal nail was replaced by a triangular area consisting of a thin nail-plate, fleshy in colour; it felt soft and could easily be indented. This abnormal nail was continuous distally with a hard thick nail which was ridged longitudinally in the midline and obliquely to each side. This part of the nail was brown in colour and was darkest and thickest centrally. Chvostek's sign and 'Trousseau's sign were negative, but there was a general increase in muscle tone, with spontaneous fasciculation over the quadriceps and bilateral ankle clonus.

Investigations at this time are shown in the Table. In addition, a glucose-tolerance test and Schilling test were normal. Barium enema showed nothing abnormal. Barium-meal examination showed multiple large jejunal diverticula and multiple round filling defects on the stomach wall and to a less extent in the duodenum. That

\section{Summary of Investigations}

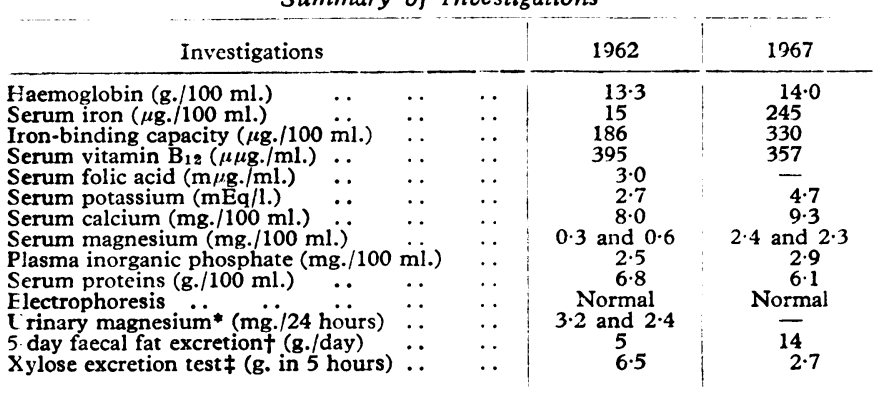

*Normal 70-120 mg./24 hours. † As stearic acid. ‡ After $25 \mathrm{~g}$. xylose by mouth.
Faecal excretion of an intravenous injection of povidone-iodine $\left({ }^{131} \mathrm{I}\right.$ polyvinylpyrrolidone) was at the upper limits of normal.

His general health is better and the alopecia is a little less diffuse, but his nails, though improved, remain abnormal.

\section{Comment}

The association of gastrointestinal polypi, alopecia, and nail dystrophy was first reported by Cronkhite and Canada (1955). Since then eight other cases have been reported. Of the nine unrelated patients, whose ages ranged from 51 to 75 years, three were males.

In our patient the appearance of the nails was distinctive and could be explained by the formation of ventral nail in the absence of normal nail production by the matrix. This has been noticed in one other patient with the Cronkhite-Canada syndrome (Shuster, personal communication) and may be a feature of it. The nail dystrophy is not pathognomonic, as it has been reported in a patient with pustular psoriasis (Samman, 1961). Alopecia and generalized pigmentation were present in all previously reported cases, but though similar diffuse hair changes had occurred in the above patient increased pigmentation was absent.

The relation between disorders of the skin and gut have recently been classified by Shuster (1967) into four groups. One cannot yet classify the Cronkhite-Canada syndrome under any of these groups, since it is not known whether the ectodermal changes are dependent on or associated with the endodermal changes.

Though our patient had only gastroduodenal involvement, polypi may involve any site of the gastrointestinal tract. A striking feature of most cases has been the severity of the symptoms and signs, which seem to be related to the extent of the polypi. Eight of the cases had diarrhoea and the faecal fat was unequivocally increased in three of the four cases in which 
the estimation was performed. Jarnum and Jensen (1966) demonstrated protein-losing enteropathy in their patient.

Five of the reported cases have had a fatal outcome (Cronkhite and Canada, 1955; Martini and Dölle, 1961 ; Johnston, Vosburgh, Wiens, and Walsh, 1962 ; Jarnum and Jensen, 1966), usually within 18 months of the onset of the diarrhoea. Spontaneous clinical and biochemical remissions occurred in one patient (Kennedy and Hirson, 1961). Two were improved by removal of the polypi-one by a gastrectomy (Manousus and Webster, 1966) and the other by a hemicolectomy (Zdansky and Riederer, 1963).

Jejunal diverticulosis and pancreatic disease have not been previously reported in this condition and it is possible that these may be part of the syndrome.

Jejunal diverticulosis is a well-recognized cause of intestinal malabsorption. Booth, Babouris, Hanna, and MacIntyre (1963) drew attention to the not uncommon finding of hypomagnesaemia, which was present in 15 out of 42 cases of intestinal malabsorption of various causes reported in their series. An interesting feature in the present case is the presentation with paraesthesiae and convulsions due to hypocalcaemia and hypomagnesaemia, and the later development of more generalized malabsorption despite symptomatic improvement and weight gain after treatment with oral supplements and broad-spectrum antibiotics.

We wish to thank Professor G. Smart, under whose care the patient was admitted, and Professor Sam Shuster for their advice and constructive criticism.

W. J. Cunliffe, M.B., B.SC., M.R.C.P., Registrar in Dermatology.

J. ANDERSON, M.B., M.R.C.P.,

First Assistant to the Department of Medicine.

University of Newcastle upon Tyne and the

Royal Victoria Infirmary, Newcastle upon Tyne.

\section{REFERENCES}

Booth, C. C., Babouris, N., Hanna, S., and Macintyre, I. (1963). Brit. med. $7 ., 2,141$

Cronkhite, L. W., and Canada, W. J. (1955). New Engl. f. Med., 252

Jarnum, S., and Jensen, H. (1966). Gastroenterology, 50, 107.

Johnston, M. M., Vosburgh, J. W., Wiems, A., T., and Walsh, G. C. (1962). Ann. intern. Med., 56, 935.

Kennedy, J. A., and Hirson, C. (1961). Proc. roy. Soc. Med., 54, 234

Martini, G. A., and Dölle, W. (1961). Dtsch. med. W schr., 86, 2524

Manousus, O., and Webster, C. U. (1966). Gut, 7, 375.

Samman, P. D. (1961). Arch. Derm., 84, 1030 .

Samman, P. D. (1961). Arch. Derm., 84, 1030. College of Physicians, London. In press.

Zdaniky, E., and Riederer, J. (1963). Radiol. clin. (Basel), 32. 254.

\section{Haemoperitoneum Associated with a Ruptured Gall Bladder}

\section{Brit. med. 9., 1967, 4, 602}

I.eared (1859) was the first to recognize that the gall bladder could be the source of catastrophic intra-abdominal haemorrhage. He described finding a ruptured gall bladder and 2 quarts (2.3 litres) of blood in the abdominal cavity of a man of 22 at a post-mortem examination. Since then the condition has been reported infrequently. Raycroft and Mastrangelo (1960) were able to collect only 18 cases from the world literature.

\section{CASE RePort}

A man of 55 was admitted to hospital on 26 January 1966. His admission was precipitated by 48 hours of severe generalized abdominal pain accompanied by abdominal distension and constipation. He gave a long history of dyspepsia-30 years previously he had had a haematemesis and since then had been subject to periodic bouts of epigastric pain relieved by food. During the year before admission he had had attacks of pain in the right lower chest and for two months had also had central abdominal colicky pains and increasing distension. A barium-meal examination shortly before admission had failed to show a cause for his dyspepsia, and six days before his admission his haemoglobin was $106 \%$.

Examination showed an obviously ill man. He was pale and clammy and had a pulse rate of 120 . The abdomen was distended and though tender all over it was particularly so in the right hypochondrium. Tenderness was also elicited on rectal examination. On auscultation bowel sounds were present. Radiographs of the abdomen showed gaseous distension of both the small and large bowel. The serum amylase was 89 Somogyi units and the haemoglobin $66 \%$.

After preliminary intravenous fluid replacement a laparotomy was performed. One and a half litres of blood and blood clot were found in the abdomen. This clearly arose from the gall bladder, which had a $2-\mathrm{cm}$. tear across Hartmann's pouch. The cystic artery was severed and blood was continuing to spurt from the proximal end. The gall bladder contained blood clot, but both it and the common bile duct appeared to be normal otherwise. No evidence of peptic ulceration was found. Cholecystectomy was performed

and the blood was removed from the abdominal cavity. Histological examination of the gall bladder showed evidence of chronic cholecystitis. The patient's postoperative progress was entirely uneventful.

\section{COMMENT}

Severe bleeding from the biliary tract is uncommon. During recent years, however, it has been shown that in a small proportion of patients with gastrointestinal haemorrhage the biliary tract is the source of the bleeding. The diagnosis has usually been made only after repeated haemorrhages have occurred and after previous gastric surgery has been undertaken (Fitzpatrick. 1961). Haemobilia has been recorded from very varied pathological causes. Minor bleeding is not uncommon in calculous cholecystitis, especially when accompanied by stones in the common bile duct, but cholecystitis appears to be the least common cause of severe bleeding. Mailer (1939), commenting on a fatal case of spontaneous rupture of the gall bladder with intraperitoneal haemorrhage, stressed the lack of inflammation in the gall bladder. Though the gall bladder in the present case showed histological evidence of chronic cholecystitis it was not the site of acute inflammation or of ischaemic necrosis. It is therefore by no means clear why the gall bladder should have ruptured, but it does seem likely that the cause was essentially a mechanical one. If the bleeding was caused by rupture of the gall bladder, the cause of the rupture remains unexplained. It is therefore thought more likely that bleeding occurred into the gall bladder first. Blood clot may have obstructed the neck of the gall bladder, leading to a rise of tension sufficient to bring about its rupture.

I am grateful to Mr. I. W. Matheson for permission to publisb this case.

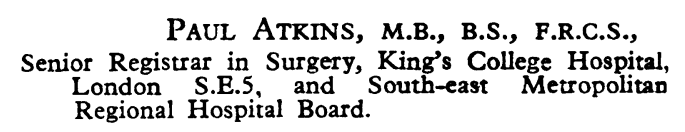

\section{REFERENCES}

Fitzpatrick, T. J. (1961). Ann. intern. Med., 55, 1008.

Fitzpatrick, T.

Leared, A. (1859). Trans. path. Soc. Lond

Raycroft, J. F., and Mastrangelo, M. (1960). Amer. F. Surg., 99, 361 